\author{
Catherine L. Tacon \\ John McCaffrey \\ Anthony Delaney
}

\section{Dobutamine for patients with severe heart failure: a systematic review and meta-analysis of randomised controlled trials}

Received: 8 July 2011

Accepted: 10 November 2011

Published online: 8 December 2011

(C) Copyright jointly held by Springer and ESICM 2011

Electronic supplementary material

The online version of this article (doi:10.1007/s00134-011-2435-6) contains supplementary material, which is available to authorized users.

\section{L. Tacon $(\bullet) \cdot$ A. Delaney}

Intensive Care Unit, Royal North Shore

Hospital, St Leonards, Sydney, NSW,

Australia

e-mail: ctacon@live.com.au

Tel.: +61-2-99267111

Fax: +61-2-94398418

J. McCaffrey

Department of Anaesthesia and Critical

Care, Belfast City Hospital, Belfast,

Northern Ireland

A. Delaney

Northern Clinical School,

University of Sydney, St Leonards,

Sydney, NSW, Australia
Abstract Purpose: Dobutamine is recommended for patients with severe heart failure; however uncertainty exists as to its effect on mortality. This study aims to critically review the literature to evaluate whether dobutamine, compared with placebo or standard care, is associated with lower mortality and a range of secondary outcomes, in patients with severe heart failure. Methods: A systematic review and meta-analysis of randomised controlled trials was performed. PubMed, EMBASE, the Cochrane Central Trials Registry, the metaRegister of Controlled Trials and bibliographies of retrieved articles were searched. Randomised trials comparing dobutamine with placebo or standard care, in human, adult patients with severe heart failure, were included if they reported at least one outcome of interest. Data regarding trial validity, methodological processes and clinical outcomes were extracted, and a meta-analysis was performed. Results: Fourteen studies, with 673 participants, met the inclusion criteria and were included; 13 studies reported mortality. There was minimal heterogeneity $\left(I^{2}=4.5 \%\right)$. The estimate of the odds ratio for mortality for patients with severe heart failure treated with dobutamine compared with standard care or placebo was 1.47 (95\% confidence interval 0.98-2.21, $p=0.06$ ). Conclusions: This meta-analysis showed that dobutamine is not associated with improved mortality in patients with heart failure, and there is a suggestion of increased mortality associated with its use, although this did not reach the conventional level of statistical significance. Further research to define the role of dobutamine in treatment of severe heart failure should be a priority.

Keywords Heart failure · Drugs . Dobutamine - Meta-analysis . Inotropic agents

\section{Introduction}

Heart failure is a significant cause of morbidity and mortality in developed countries, and its prevalence is increasing [1]. In 2009, the prevalence of heart failure was estimated to be more than $15,000,000$ throughout the European continent [1] and 5,800,000 in the USA [2]. With hospital mortality of approximately $12 \%$ [3], heart failure is clearly a significant issue. For patients with moderate heart failure, good evidence exists to guide therapy with angiotensin-converting enzyme inhibitors $[4,5]$, aldosterone antagonists $[6,7]$ and cardiac resynchronisation therapy [8], all of which result in significant reductions in mortality. Furthermore, of particular note is the reduction in mortality that is associated with use of beta blockers [9-13] in the management of heart failure.

When patients with more severe cardiac failure decompensate, they generally require escalated supportive 
therapy. Use of non-invasive ventilation to support patients with acute pulmonary oedema due to decompensated heart failure is supported by high-level evidence [14]. However, for patients with acute heart failure who develop symptoms related to low cardiac output and poor tissue perfusion, there is little strong evidence to guide clinicians. Current clinical guidelines recommend use of inotropic agents [1] in such patients. Dobutamine remains a recommended inotrope in international guidelines [1] and is commonly used in patients admitted with severe heart failure [3]. Dobutamine is a synthetic sympathomimetic amine which stimulates $\beta 1$ and to a lesser extent $\beta 2$ receptors to produce a dose-dependent inotropic and chronotropic response [15]. While this leads to an increase in cardiac output, myocardial oxygen demand is also increased, increasing the risk of myocardial ischaemia, tachyarrhythmias and ventricular dysfunction [15]. While dobutamine remains recommended for use, there remains concern and uncertainty regarding the balance of benefit and harm associated with its use in this population [16].

The principal aim of this study is therefore to critically review the literature to evaluate whether dobutamine, compared with placebo or standard care, is associated with lower mortality, as well as a range of secondary outcomes, in patients with severe heart failure.

\section{Methods}

We sought prospective randomised clinical trials that compared dobutamine with either placebo or standard care for inclusion in this review. Only studies that included adult participants were considered for inclusion. There were no language restrictions placed on the search. Studies needed to report mortality, for any length of follow-up, or one of the secondary outcomes of the study to be considered eligible for inclusion.

The electronic search for randomised control trials (RCTs) was conducted using PubMed, EMBASE and the Cochrane Central Trials Registry. The PubMed inquiry used search terms "dobutamine" [MESH] and "heart failure" [MESH], with a sensitivity filter for RCTs [17]. EMBASE was searched using terms "dobutamine" combined with "severe heart failure" and a sensitivity filter for RCTs [18]. The Cochrane Central Trials Registry was searched using "dobutamine" combined with "heart failure". No language restrictions were used. The search was performed independently by three investigators (C.L.T., A.D. and J.M.) and was completed on 11 February 2011. The metaRegister of Controlled Trials (http://www. controlled-trials.com/mrct) including the medical editors trials amnesty was also searched using the term "dobutamine". Finally, bibliographies of retrieved articles, previous review articles and meta-analyses were reviewed to identify any additional unpublished or unrecognised trials.
Two authors (C.L.T. and A.D.) reviewed all abstracts to determine if they could potentially meet the inclusion criteria. Full-text reports or abstracts were retrieved for full review by two authors (C.L.T. and A.D.) to determine if they met the eligibility criteria. Disputes were resolved by discussion, with resort to a third investigator (J.M.) if needed. Studies considered eligible for inclusion were RCTs of dobutamine compared with placebo or no specific additional treatment other than standard care, in human, adult patients with severe heart failure [as defined by New York Heart Association (NYHA) classification III or IV]. For inclusion the study must have reported at least one outcome of interest. These outcomes were: mortality, length of stay in intensive care, coronary care unit or hospital, arrhythmias, acute myocardial infarction and change in symptoms. Studies that failed to meet more than one inclusion criteria were classified as not relevant.

All included studies were assessed independently by two authors (C.L.T. and A.D.) for validity. Any disagreements were resolved by discussion. A component approach to the assessment of the validity of the included studies was utilised [19]. The validity criteria assessed were use of a randomisation method that maintained allocation concealment, use of blinding for outcome assessment, presentation of an intention-to-treat analysis [20] and presentation of predefined outcomes. We also assessed the degree of loss to follow-up and baseline differences between the control and treatment groups. When the report did not contain sufficient information to assess the validity criteria, attempts were made to contact the authors by email. If it remained unclear if a criterion was present, it was assessed as being absent [20].

Data were extracted independently by the two authors onto specific data collection forms. Data collected included the baseline characteristics of the study and control groups (including inpatient or outpatient population defined as where the patients were recruited into the study), demographics of the study groups, heart failure definition used in the study, dose and duration of dobutamine therapy, duration of follow-up, haemodynamic and clinical outcomes. Again if outcome data were not clearly presented, attempts were made to contact the authors by email.

The potential for small study bias was assessed by use of a funnel plot and the statistical test described by Egger [21]. Heterogeneity among studies was assessed using the $I^{2}$ statistic, with $I^{2}>50 \%$ indicating at least moderate heterogeneity [22], and a $\chi^{2}$ test. We planned to pool the mortality results for the primary analysis using a fixed effect model [23] to produce a pooled odds ratio (OR) [24]. Sensitivity analysis was performed by combining the results with a random effects model. We assessed the effect of validity parameters (blinding, allocation concealment and intentionto-treat analysis), population included in the RCT (inpatient versus outpatient) and comparison group (placebo or standard care) on the estimate of treatment effect, by assessing the interaction term in a single covariate meta-regression analysis. An influence analysis was undertaken to assess the 
estimate of treatment effect with each study that reported at least one event omitted from the analysis. Other outcomes were reported too infrequently and inconsistently to allow reasonable synthesis, apart from symptomatic improvements which were simply tabulated. All analyses were performed using STATA 11.1 (College Station, TX).

\section{Results}

The search returned a total of 654 reports. After application of the inclusion criteria, 14 studies [25-38] including a total of 673 participants were included in the systematic review, and 13 [25, 27-38] studies reported mortality data and were included in the meta-analysis. One study reported a change in symptoms and was included in the qualitative synthesis only [26]. The flow of studies and reasons for exclusion are shown in Fig. 1.

The characteristics of the included studies are presented in Table 1 . The results of the validity assessments of the included studies are presented in Table 2. It is noteworthy that only three studies described an adequate method of allocation concealment and only two studies met all of the validity criteria.

Mortality data were available in 13 studies. There was no asymmetry of the funnel plot (shown as Electronic Appendix 1), nor was there evidence of bias as assessed by Egger's test (bias $=-0.45, p=0.35$ ). There was minimal heterogeneity $\left(I^{2}=4.5 \%\right)$. The pooled result of the 13 studies reporting mortality is shown in Fig. 2. The estimate of the OR for mortality for patients with severe heart failure treated with dobutamine compared with standard care or placebo was 1.47 (95\% confidence interval $0.98-2.21, p=0.06$ ).

The result of the pooled analysis was similar when a random effects model was used to pool the results, with an estimate of the OR for mortality associated with the use of dobutamine compared with placebo for patients with severe heart failure of 1.44 (95\% confidence limits 0.92-2.27, $p=0.11$ ). The results of the pre-specified subgroup analysis based upon the validity assessments, patient populations and control group are presented in Table 3. There was no evidence that the effect of dobutamine was different in patients who were recruited in an inpatient setting (OR $1.48,95 \%$ confidence limits $0.9-2.46, p=0.13$ ) compared with those who were recruited in an outpatient setting (OR $1.47,95 \%$ confidence limits $0.98-2.21, p=0.29$ ), with the test for the interaction non-significant $(p=0.84)$, as shown in Appendix 2. There was no evidence that any aspect of study validity was associated with a differential estimate of treatment effect. There was no evidence that any of the studies exerted undue influence over the pooled results, as shown in Electronic Appendix 3.

Symptomatic improvements following administration of dobutamine or placebo were not reported in a

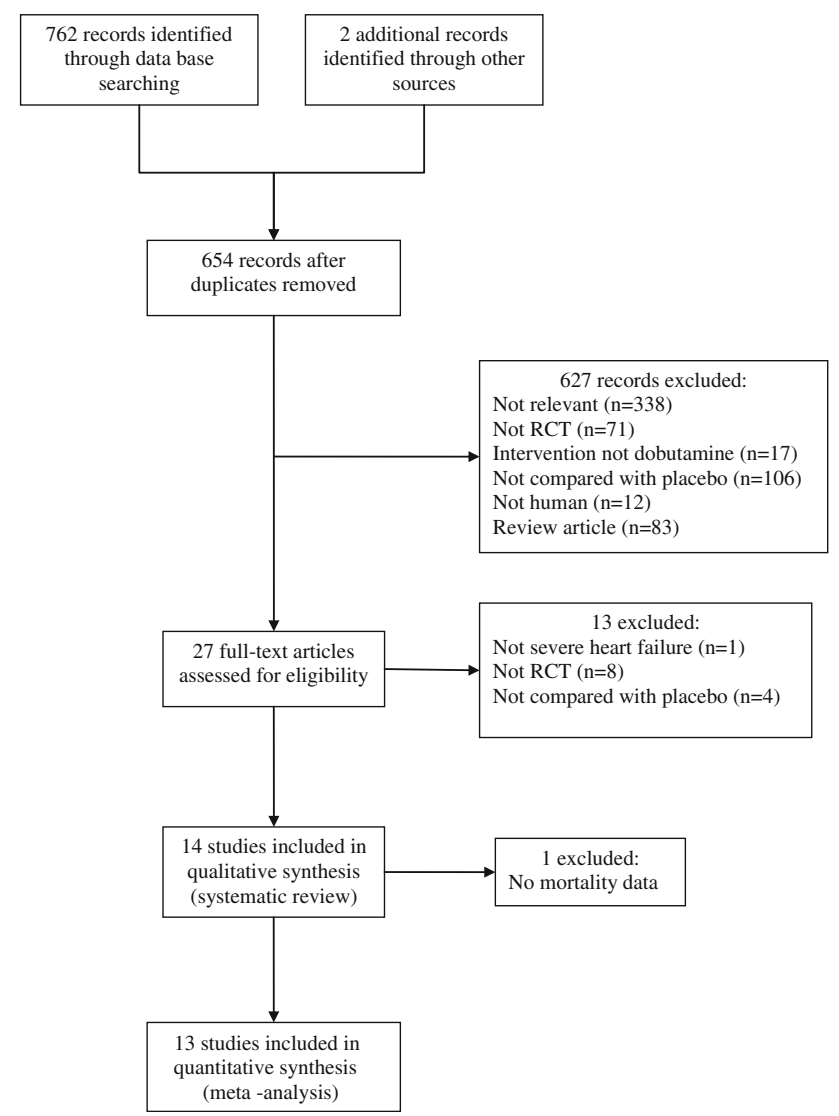

Fig. 1 Flow diagram showing the results of the search and reasons for exclusion of studies

sufficiently comparable fashion to allow pooled analysis. Table 4 presents a summary of the reports of the effect of dobutamine compared with placebo on symptoms in patients with severe heart failure. Table 4 also presents a summary of the adverse events reported in each trial.

\section{Discussion}

We performed a systematic review and meta-analysis to assess the effect of dobutamine compared with control for patients with severe heart failure. While there are a significant number of trials that have assessed this relationship, all are relatively small and the methodological quality of the reports is poor. Dobutamine is not associated with improved mortality in patients with heart failure, and there is some suggestion of increased mortality associated with use of dobutamine in patients with severe heart failure, although this did not reach the conventional level of statistical significance. The reporting of symptomatic improvements or adverse events was not sufficiently standardised to allow general conclusions to be drawn, although there was no clear evidence that dobutamine was associated with improvements in 


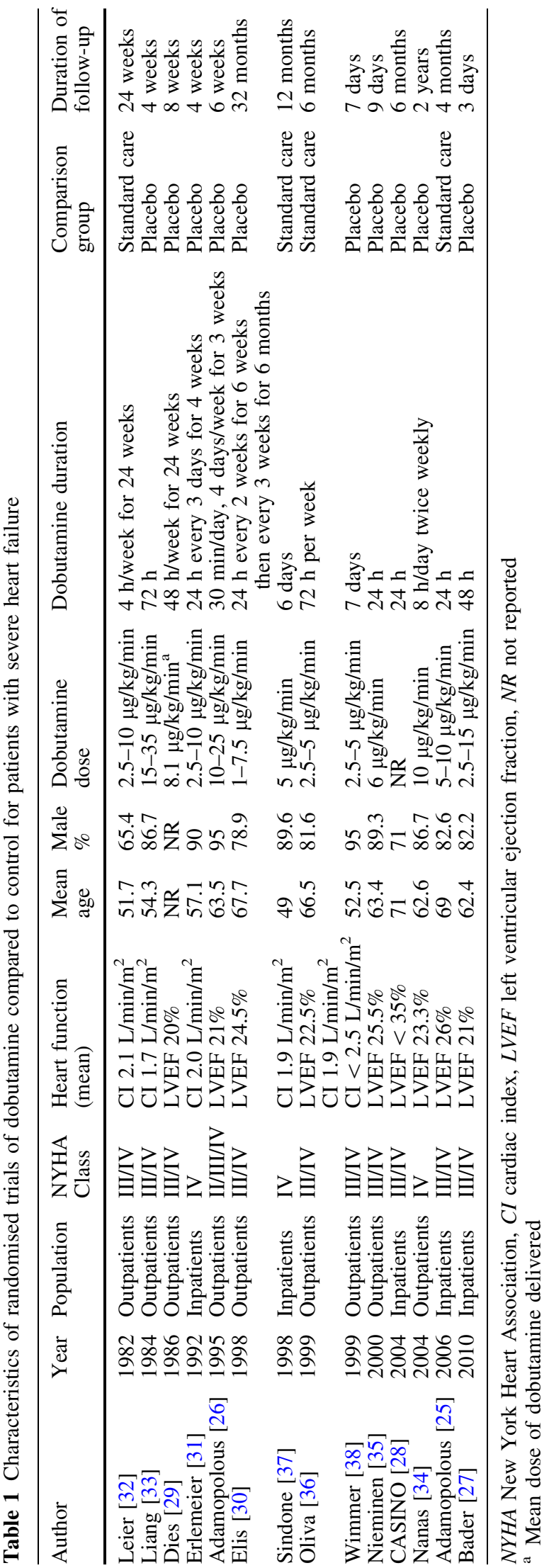

symptoms in patients with severe heart failure. These data would suggest that clinicians should be cautious about use of dobutamine in patients with severe heart failure.

Conventional medical treatment for patients with severe cardiac failure would include use of agents to improve cardiac output [1]. It is clear that dobutamine, acting via $\mathrm{B}$ adrenergic receptors, will increase heart rate and contractility and lead to improved cardiac output $[39,40]$; it will also increase myocardial oxygen consumption [39]. However, just as use of anti-arrhythmic drugs reduced ventricular ectopy while increasing mortality [41], improvements in surrogate outcomes, such as cardiac output, are not always associated with improved patient-oriented outcomes, such as mortality. As approximately $70 \%$ of patients in Western societies who develop heart failure do so as a consequence of underlying ischaemic heart disease [42], it is possible that induction of myocardial ischaemia and subsequent myocardial infarction and dysrhythmias would act as a mechanism by which dobutamine could lead to an increase in mortality [43].

It must be noted that the estimate of the OR for mortality, while favouring use of placebo or standard care over dobutamine, did not reach the conventional threshold for statistical significance and that the observed increase in mortality associated with use of dobutamine may be a chance finding. There are also limitations to this study that warrant consideration when interpreting the results. The quality of the reports of the RCTs included in this systematic review was suboptimal. In particular, only three RCTs reported a method of randomisation that maintained allocation concealment. As lack of allocation concealment is associated with bias of up to $40 \%$ [20], the fact that this aspect of the RCTs was so poorly reported leaves some doubt as to the results. The standard care delivered to the participants in these was often poorly specified, varied between the studies and likely changed over time. This could affect the external validity of the results of this review. The duration of follow-up in the included studies varied greatly. It was notable that the studies with longer follow-up tended to favour dobutamine. Further research in this field should have a standardised duration of followup that takes into account the mortality associated with the underlying pathology. There were three studies included in this meta-analysis that were published only as abstracts, and these studies accounted for more than $50 \%$ of the weighted results in the pooled analysis. It is notable that the CASINO [28] study, including almost 600 patients, has never passed through the scrutiny of peer review. Serious questions have been raised at the non-publication of the results of studies such as this $[44,45]$. The conclusions that can be drawn from the results of this meta-analysis are also hampered by the lack of reporting of other outcomes of interest such as intensive care unit (ICU) and hospital length of stay, and in particular adverse events that might be attributable to dobutamine such as episodes of myocardial ischaemia, as well as the inconsistent reporting of 
Table 2 Summary of the validity assessments of randomised clinical trials of dobutamine compared to control in patients with severe heart failure

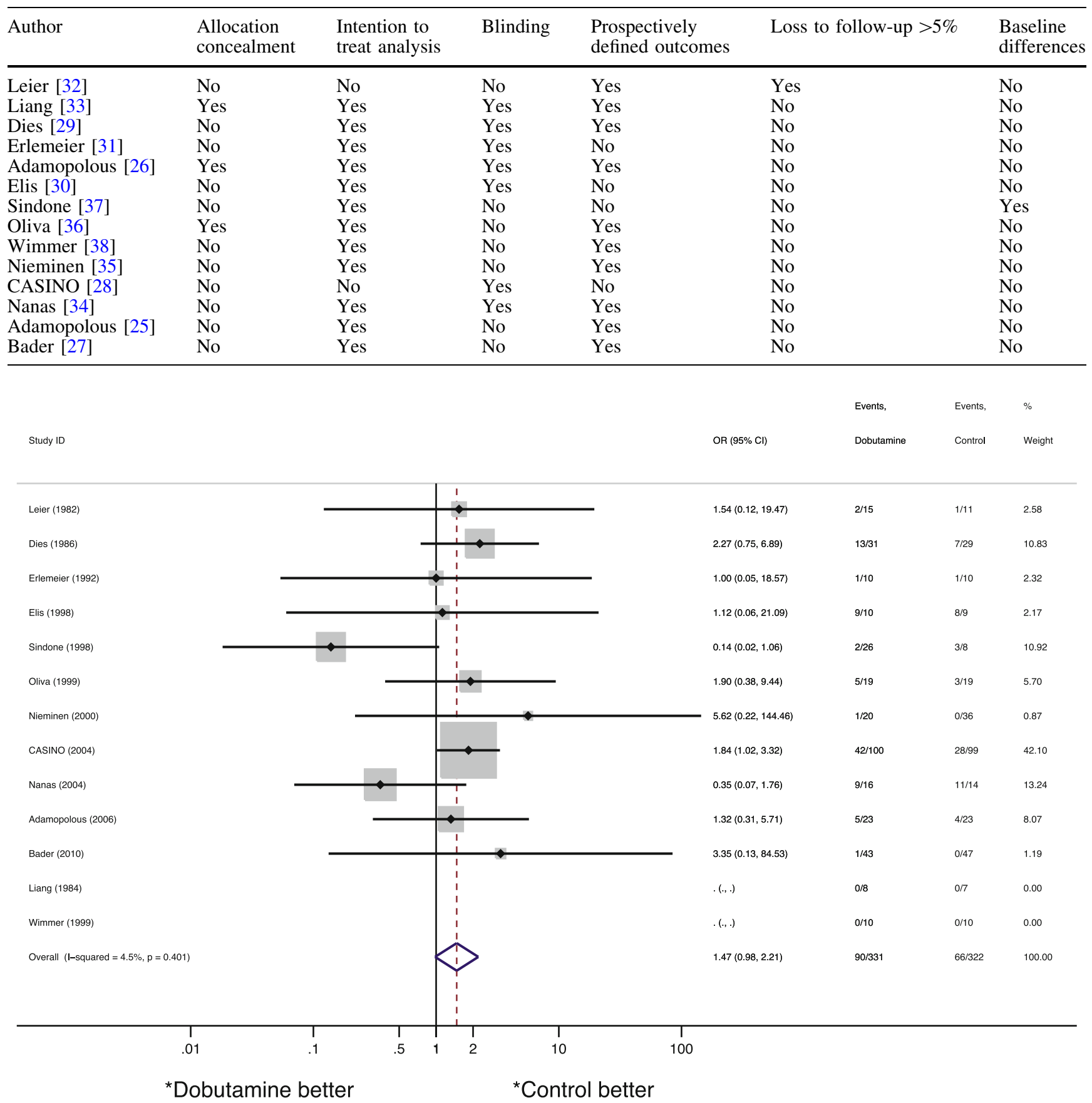

Fig. 2 Forrest plot showing the pooled estimate of the odds ratio for mortality for dobutamine compared with placebo or standard care in patients with severe heart failure

other patient-focussed outcomes such as improvements in symptoms. Finally, while it is noted that there was little statistical heterogeneity apparent in this study, there was considerable clinical heterogeneity. The dosing regimens and duration of administration were quite variable. It is also possible that the effect of dobutamine may be different in differing sub-populations, such as those with and without ischaemic heart disease. It is not possible to unravel these effects in a meta-analysis without individual patient data, data not available in this study. Further studies should consider choosing more homogeneous populations and a common dosing regimen. 
Table 3 Results of subgroup analysis

\begin{tabular}{lclll}
\hline Subgroup & Number of studies & Estimate of OR & $95 \%$ CI & $P$ value for interaction \\
\hline $\begin{array}{l}\text { Allocation concealment } \\
\text { Yes }\end{array}$ & 2 & & & \\
$\quad$ No & 11 & 1.91 & $0.38-9.44$ & 0.69 \\
$\begin{array}{l}\text { Blinding } \\
\quad \text { Yes }\end{array}$ & 6 & 1.45 & $0.95-2.2$ & \\
$\quad$ No & 7 & 1.22 & $0.56-2.68$ & 0.64 \\
$\begin{array}{l}\text { Intention to treat } \\
\quad \text { Yes }\end{array}$ & 11 & 1.58 & $0.98-2.53$ & \\
$\quad$ No & 2 & 1.19 & $0.67-2.12$ & 0.41 \\
$\begin{array}{l}\text { Population } \\
\text { Inpatient }\end{array}$ & 5 & 1.82 & $1.02-3.23$ & \\
$\quad \begin{array}{l}\text { Outpatient } \\
\text { Control group }\end{array}$ & 8 & 1.45 & $0.73-2.88$ & 0.84 \\
$\quad \begin{array}{l}\text { Standard care } \\
\text { Placebo }\end{array}$ & 4 & 1.48 & $0.98-2.21$ & \\
\hline
\end{tabular}

$O R$ odds ratio, $C I$ confidence interval

Table 4 Summary of reports of symptomatic changes and adverse events in trials comparing dobutamine and control

\begin{tabular}{|c|c|c|}
\hline Study & Symptomatic change & Adverse events \\
\hline Leier [32] & $\begin{array}{l}\text { 2/11 (control) vs. } 12 / 15 \text { (dobutamine) improved at least one } \\
\text { NYHA class }\end{array}$ & NR \\
\hline Liang [33] & $\begin{array}{l}\text { 2/7 (control) vs. } 6 / 8 \text { (dobutamine) improved at least one } \\
\text { NYHA class }\end{array}$ & NR \\
\hline $\begin{array}{l}\text { Adamopolous } \\
{[26]}\end{array}$ & $\begin{array}{l}\text { Mean breathlessness score; } 3.0 / 7 \text { (control) vs. } 1.8 / 7 \\
\quad(\text { dobutamine), } p<0.05 \\
\text { Mean tiredness score; } 3.4 / 7 \text { (control) vs. } 2.6 / 7 \text { dobutamine), } \\
\quad p<0.05\end{array}$ & NR \\
\hline Elis [30] & $\begin{array}{l}\text { Mean admissions to hospital for heart failure } 2.1 \text { (control) } \\
\text { vs. } 2.2 \text { (dobutamine), } p=0.11\end{array}$ & NR \\
\hline Sindone [37] & $\begin{array}{l}\text { Spielberger anxiety questionnaire; } 24 \% \text { reduction (control) } \\
\text { vs. } 24 \% \text { reduction (dobutamine) } \\
\text { General health questionnaire; } 43 \% \text { reduction (control) vs. } \\
40 \% \text { reduction (dobutamine) }\end{array}$ & NR \\
\hline Oliva [36] & $\begin{array}{l}5 \text { (control) vs. } 7 \text { (dobutamine) required hospitalisation for } \\
\text { heart failure } \\
\text { Median NYHA class at } 6 \text { months; } 3 \text { (control) and } 2.5 \\
\text { (dobutamine) }\end{array}$ & $\begin{array}{l}1 \text { (dobutamine) showed increased rate of non- } \\
\text { sustained VT on Holter }\end{array}$ \\
\hline Wimmer [38] & NR & $\begin{array}{l}2 \text { (dobutamine) complained of repeated } \\
\text { palpitations }\end{array}$ \\
\hline Nieminen [35] & NR & $\begin{array}{l}20 \% \text { (placebo) vs. } 35 \% \text { (dobutamine) reported } \\
\text { adverse events including hypertension, } \\
\text { tachycardia and arrhythmias } \\
1 \text { (control) vs. } 5 \text { (dobutamine) experienced } \\
\text { tachycardia }\end{array}$ \\
\hline Nanas [34] & $\begin{array}{l}\text { Mean NYHA at } 6 \text { months fell from } 4 \text { to } 2.2 \text { (control) and } \\
\text { from } 4 \text { to } 2.3 \text { (dobutamine) }\end{array}$ & NR \\
\hline Bader [27] & NR & $\begin{array}{l}2 \text { (control) vs. } 0 \text { (dobutamine) experienced } \\
\text { sustained VT } \\
6 \text { (control) vs. } 11 \text { (dobutamine) experienced new- } \\
\text { onset SVT } \\
3 \text { (control) vs. } 9 \text { (dobutamine) experienced } \\
\text { dysrhythmia } \\
6 \text { (control) vs. } 18 \text { (dobutamine) met Morganroth } \\
\text { criteria for pro-arrhythmia }\end{array}$ \\
\hline
\end{tabular}

NYHA New York heart association, VT ventricular tachycardia, SVT Supraventricular tachycardia, NR Not reported

There were a number of strengths of this review. The methods of the study closely paralleled current guidelines for the reporting of systematic reviews [46]. We were able to locate a number of unpublished studies, and there was no evidence of small study or publication bias. The pooled estimate of treatment was robust to the method used to combine the results, and there was little heterogeneity amongst the included studies. 
Given the strengths and limitations of this study, what are the implications for clinicians? The results of this study alone, given the lack of a strong statistically significant result, and the poor methodological quality of the included studies, may not be sufficient to drive a change in clinical practice. It should be noted that the results of this study are in accord with large observational studies that have also suggested harm associated with use of dobutamine in patients with severe heart failure $[47,48]$. Taken together, this evidence should cause clinicians to reconsider their use of dobutamine in patients with heart failure, particularly those most at risk of the adverse effects, those with underlying ischaemic heart disease. There is already significant doubt regarding the efficacy of alternative agents such as milrinone, particularly in patients with cardiac failure due to underlying ischaemic heart disease [49]. Other inotropic agents such as calcium sensitisers have been suggested to be of use for patients who present with severe heart failure who are deemed to require inotropic support, although the efficacy of such agents is yet to be proven in large-scale clinical trials [50, 51].

Use of inotropic agents is still recommended in the guidelines for treatment of severe acute heart failure [1,52]. There are certainly some patients with low cardiac output who appear to benefit in the short term from administration of positive inotropic agents such as dobutamine, yet there is little apparent longer-term mortality benefit from administration of these medications. Further research to define a population of patients most likely to benefit, or conversely to define a population most likely to experience harm, from the administration of dobutamine appears to be a priority. While the reference standard for the determination of efficacy of an agent such as dobutamine would be a placebo- controlled RCT, the feasibility and logistics of conducting such a trial would be challenging.

\section{Conclusions}

This systematic review of the effect of dobutamine on mortality in severe heart failure found a total of 14 studies, of which 13 reported mortality data that were included in the meta-analysis. Dobutamine was not found to be associated with improved mortality in patients with heart failure, and a trend towards an increase in mortality with use of dobutamine compared with placebo or standard care was evident, although this did not reach statistical significance. Overall, the included studies had a poor level of methodological reporting, with several only being published in abstract form, limiting the conclusions that can be made from this meta-analysis. However, given the widespread use of dobutamine in management of severe heart failure, further methodologically sound studies would be beneficial to identify which patient populations are most likely to receive benefit, or indeed harm, from this agent.

Acknowledgments The authors would like to thank Melissa Passer (North Shore Private Hospital Critical Care Research Fellow) for her assistance in locating articles, Dr. Jan Wiegand for his translation of articles, and Dr. Chang-Seng Liang, Prof. Richard Pacher, Prof. Andrew Sindone, Prof. Anne Keogh, Prof. Peter Macdonald and Dr. Dennis Cokkinas for their correspondence regarding their publications. We gratefully acknowledge Dr. Ray Raper for his insightful comments on this manuscript.

Conflict of interest The authors have no conflicts of interest.

\section{References}

1. Dickstein K, Cohen-Solal A, Filippatos G, McMurray JJ, Ponikowski P, PooleWilson PA, Stromberg A, van Veldhuisen DJ, Atar D, Hoes AW, Keren A, Mebazaa A, Nieminen M, Priori SG, Swedberg K, Vahanian A, Camm J, De Caterina R, Dean V, Funck-Brentano C, Hellemans I, Kristensen SD, McGregor K, Sechtem U, Silber S, Tendera M, Widimsky P, Zamorano JL (2008) ESC guidelines for the diagnosis and treatment of acute and chronic heart failure 2008: the task force for the diagnosis and treatment of acute and chronic heart failure 2008 of the European Society Of Cardiology. Developed in collaboration with the Heart Failure Association of the ESC (HFA) and endorsed by the European Society of Intensive Care Medicine (ESICM). Eur Heart J 29:2388-2442. doi:10.1093/eurheartj/ehn309
2. Weintraub NL, Collins SP, Pang PS, Levy PD, Anderson AS, ArslanianEngoren C, Gibler WB, McCord JK, Parshall MB, Francis GS, Gheorghiade M (2010) Acute heart failure syndromes: emergency department presentation, treatment, and disposition: current approaches and future aims: a scientific statement from the American Heart Association. Circulation 122:1975-1996. doi:

10.1161/CIR.0b013e3181f9a223

3. Follath F, Yilmaz MB, Delgado JF, Parissis JT, Porcher R, Gayat E, Burrows N, McLean A, Vilas-Boas F, Mebazaa A (2011) Clinical presentation, management and outcomes in the acute heart failure global survey of standard treatment (ALARM-HF). Intensive Care Med. doi:10.1007/s00134-010-2113-0
4. CONSENSUS (1987) Effects of enalapril on mortality in severe congestive heart failure. Results of the Cooperative North Scandinavian Enalapril Survival Study (CONSENSUS). The CONSENSUS Trial Study Group. N Engl J Med 316:1429-1435. doi: 10.1056/NEJM198706043162301

5. SOLVD (1991) Effect of enalapril on survival in patients with reduced left ventricular ejection fractions and congestive heart failure. The SOLVD Investigators. N Engl J Med 325:293-302. doi:10.1056/NEJM 199108013250501 
6. Pitt B, Zannad F, Remme WJ, Cody R, 15. Triposkiadis F, Parissis JT, Starling RC, Castaigne A, Perez A, Palensky J, Wittes J (1999) The effect of spironolactone on morbidity and mortality in patients with severe heart failure. Randomized Aldactone Evaluation Study Investigators. N Engl J Med 341:709-717. doi: 10.1056/NEJM199909023411001

7. Zannad F, McMurray JJ, Krum H, van Veldhuisen DJ, Swedberg K, Shi H, Vincent J, Pocock SJ, Pitt B (2011) Eplerenone in patients with systolic heart failure and mild symptoms. N Engl J Med 364:11-21. doi: 10.1056/NEJMoa1009492

8. Rivero-Ayerza M, Theuns DA, GarciaGarcia HM, Boersma E, Simoons M, Jordaens LJ (2006) Effects of cardiac resynchronization therapy on overall mortality and mode of death: a metaanalysis of randomized controlled trials. Eur Heart J 27:2682-2688. doi: 10.1093/eurheartj/ehl203

9. II CIBIS- (1999) The Cardiac Insufficiency Bisoprolol Study II (CIBIS-II): a randomised trial. Lancet 353:9-13. doi:S0140673698111819

10. Lechat $P$, Packer $M$, Chalon S, Cucherat M, Arab T, Boissel JP (1998) Clinical effects of beta-adrenergic blockade in chronic heart failure: a meta-analysis of double-blind, placebocontrolled, randomized trials.

Circulation 98:1184-1191

11. HF MERIT- (1999) Effect of metoprolol CR/XL in chronic heart failure: Metoprolol CR/XL Randomised Intervention Trial in congestive heart failure (MERIT-HF). Lancet 353:2001-2007. doi:S01406736 99044402

12. Packer M, Coats AJ, Fowler MB, Katus HA, Krum H, Mohacsi P, Rouleau JL, Tendera M, Castaigne A, Roecker EB, Schultz MK, DeMets DL (2001) Effect of carvedilol on survival in severe chronic heart failure. N Engl J Med 344:1651-1658. doi: 10.1056/NEJM200105313442201

13. Packer M, Fowler MB, Roecker EB, Coats AJ, Katus HA, Krum H, Mohacsi P, Rouleau JL, Tendera M, Staiger C, Holcslaw TL, Amann-Zalan I, DeMets DL (2002) Effect of carvedilol on the morbidity of patients with severe chronic heart failure: results of the carvedilol prospective randomized cumulative survival (COPERNICUS) study. Circulation 106:2194-2199

14. Masip J, Roque M, Sanchez B, Fernandez R, Subirana M, Exposito JA (2005) Noninvasive ventilation in acute cardiogenic pulmonary edema: systematic review and meta-analysis. JAMA 294:3124-3130. doi:10.1001/jama.294.24.3124
Skoularigis J, Louridas G (2009)

Current drugs and medical treatment algorithms in the management of acute decompensated heart failure. Expert Opin Investig Drugs 18:695-707. doi: $10.1517 / 13543780902922660$

16. Parissis JT, Rafouli-Stergiou P, Stasinos V, Psarogiannakopoulos P, Mebazaa A (2010) Inotropes in cardiac patients: update 2011. Curr Opin Crit Care 16:432-441. doi: 10.1097/MCC.0b013e32833e10fb

17. Haynes RB, McKibbon KA, Wilczynski NL, Walter SD, Werre SR (2005) Optimal search strategies for retrieving scientifically strong studies of treatment from medline: analytical survey. BMJ 330:1179

18. Wong SS, Wilczynski NL, Haynes RB (2006) Developing optimal search strategies for detecting clinically sound treatment studies in EMBASE. J Med Libr Assoc 94:41-47

19. Juni P, Altman DG, Egger M (2001) Systematic reviews in health care: assessing the quality of controlled clinical trials. BMJ 323:42-46

20. Schulz KF, Chalmers I, Hayes RJ, Altman DG (1995) Empirical evidence of bias. Dimensions of methodological quality associated with estimates of treatment effects in controlled trials. JAMA 273:408-412

21. Egger M, Davey Smith G, Schneider M, Minder C (1997) Bias in meta-analysis detected by a simple, graphical test. BMJ 315:629-634

22. Higgins JP, Thompson SG, Deeks JJ, Altman DG (2003) Measuring inconsistency in meta-analyses. BMJ 327:557-560

23. Villar J, Mackey ME, Carroli G, Donner A (2001) Meta-analyses in systematic reviews of randomized controlled trials in perinatal medicine: comparison of fixed and random effects models. Stat Med 20:3635-3647

24. Deeks JJ (2002) Issues in the selection of clinical trials with binary outcomes. Stat Med 21:1575-1600

25. Adamopoulos S, Parissis JT, Iliodromitis EK, Paraskevaidis I, Tsiapras D, Farmakis D, Karatzas D, Gheorghiade M, Filippatos GS, Kremastinos DT (2006) Effects of levosimendan versus dobutamine on inflammatory and apoptotic pathways in acutely decompensated chronic heart failure. Am J Cardiol 98:102-106

26. Adamopoulos S, Piepoli M, Qiang F, Pissimissis E, Davies M, Bernardi L, Forfar C, Sleight P, Coats A (1995) Effects of pulsed beta-stimulant therapy on beta-adrenoceptors and chronotropic responsiveness in chronic heart failure. Lancet 345:344-349 of a summary statistic for meta-analysis
27. Bader FM, Gilbert EM, Mehta NA, Bristow MR (2010) Double-blind placebo-controlled comparison of enoximone and dobutamine infusions in patients with moderate to severe chronic heart failure. Congest Heart Fail 16:265-270. doi:10.1111/j.17517133.2010.00185.x

28. Cleland JG, Ghosh J, Freemantle N, Kaye GC, Nasir M, Clark AL, Coletta AP (2004) Clinical trials update and cumulative meta-analyses from the American College of Cardiology: WATCH, SCD-HeFT, DINAMIT, CASINO, INSPIRE, STRATUS-US, RIO-Lipids and cardiac resynchronisation therapy in heart failure. Eur J Heart Fail 6:501-508

29. Dies F, Krell MJ, Whitlow P, Liang C-S, Goldenberg I, Applefield MM Gilbert EM (1986) Intermittent dobutamine in ambulatory outpatients with chronic heart failure. Circulation 74:II-38

30. Elis A, Bental T, Kimchi O, Ravid M, Lishner M (1998) Intermittent dobutamine treatment in patients with chronic refractory congestive heart failure: a randomized, double-blind, placebo-controlled study. Clin Pharmacol Ther 63:682-685

31. Erlemeier HH, Kupper W, Bleifeld W (1992) Intermittent infusion of dobutamine in the therapy of severe congestive heart failure-long-term effects and lack of tolerance. Cardiovasc Drugs Ther 6:391-398

32. Leier CV, Huss P, Lewis RP, Unverferth DV (1982) Drug-induced conditioning in congestive heart failure. Circulation 65:1382-1387

33. Liang CS, Sherman LG, Doherty JU, Wellington K, Lee VW, Hood WB (1984) Sustained improvement of cardiac function in patients with congestive heart failure after short-term infusion of dobutamine. Circulation 69:113-119

34. Nanas JN, Tsagalou EP, Kanakakis J, Nanas SN, Terrovitis JV, Moon T, Anastasiou-Nana MI (2004) Long-term intermittent dobutamine infusion, combined with oral amiodarone for end-stage heart failure: a randomized double-blind study. Chest 125:1198-1204

35. Nieminen MS, Akkila J, Hasenfuss G, Kleber FX, Lehtonen LA, Mitrovic V, Nyquist O, Remme WJ (2000) Hemodynamic and neurohumoral effects of continuous infusion of levosimendan in patients with congestive heart failure. J Am Coll Cardiol 36:1903-1912 
36. Oliva F, Latini R, Politi A, Staszewsky L, Maggioni AP, Nicolis E, Mauri F (1999) Intermittent 6-month low-dose dobutamine infusion in severe heart failure: DICE multicenter trial. Am Heart J 138:247-253

37. Sindone AP, MacDonald PS, Keogh AM (1998) Haemodynamic, neurohumoral and symptomatic effects of dobutamine, dopamine and milrinone in severe heart failure. [abstract]. Aust N Z J Med 28:113

38. Wimmer A, Stanek B, Kubecova L, Vitovec J, Spinar J, Yilmaz N, Kos T, Hartter E, Frey B, Pacher R (1999) Effects of prostaglandin E1, dobutamine and placebo on hemodynamic, renal and neurohumoral variables in patients with advanced heart failure. Jpn Heart J 40:321-334

39. Grose R, Strain J, Greenberg M, LeJemtel TH (1986) Systemic and coronary effects of intravenous milrinone and dobutamine in congestive heart failure. J Am Coll Cardiol 7:1107-1113

40. Petersen JW, Felker GM (2008) Inotropes in the management of acute heart failure. Crit Care Med 36:S106S111. doi:10.1097/01.CCM. 0000296273.72952.39

41. Echt DS, Liebson PR, Mitchell LB, Peters RW, Obias-Manno D, Barker AH, Arensberg D, Baker A, Friedman L, Greene HL et al (1991) Mortality and morbidity in patients receiving encainide, flecainide, or placebo. The Cardiac Arrhythmia Suppression Trial. N Engl J Med 324:781-788

42. Dar O, Cowie MR (2008) Acute heart failure in the intensive care unit: epidemiology. Crit Care Med 36:S3-S8. doi:10.1097/01.CCM. 0000296264.41365 .80
43. Lehtonen LA, Antila S, Pentikainen PJ (2004) Pharmacokinetics and pharmacodynamics of intravenous inotropic agents. Clin Pharmacokinet 43:187-203

44. Chalmers I (1990) Underreporting research is scientific misconduct. JAMA 263:1405-1408

45. Shields PG (2000) Publication bias is a scientific problem with adverse ethical outcomes: the case for a section for null results. Cancer Epidemiol Biomarkers Prev 9:771-772

46. Liberati A, Altman DG, Tetzlaff J, Mulrow C, Gotzsche PC, Ioannidis JP, Clarke M, Devereaux PJ, Kleijnen J, Moher D (2009) The PRISMA statement for reporting systematic reviews and meta-analyses of studies that evaluate health care interventions: explanation and elaboration. J Clin Epidemiol 62:e1-e34. doi: 10.1016/j.jclinepi.2009.06.006

47. Abraham WT, Adams KF, Fonarow GC, Costanzo MR, Berkowitz RL, LeJemtel TH, Cheng ML, Wynne J (2005) In-hospital mortality in patients with acute decompensated heart failure requiring intravenous vasoactive medications: an analysis from the Acute Decompensated Heart Failure National Registry (ADHERE). J Am Coll Cardiol 46:57-64. doi:10.1016/ j.jacc.2005.03.051

48. Mebazaa A, Parissis J, Porcher R, Gayat E, Nikolaou M, Boas FV, Delgado JF, Follath F (2011) Short-term survival by treatment among patients hospitalized with acute heart failure: the global ALARM-HF registry using propensity scoring methods. Intensive Care Med 37:290-301. doi:10.1007/s00134010-2073-4
49. Felker GM, Benza RL, Chandler AB, Leimberger JD, Cuffe MS, Califf RM, Gheorghiade M, O'Connor CM (2003) Heart failure etiology and response to milrinone in decompensated heart failure: results from the OPTIME-CHF study. J Am Coll Cardiol 41:997-1003

50. Mebazaa A, Nieminen MS, Packer M, Cohen-Solal A, Kleber FX, Pocock SJ, Thakkar R, Padley RJ, Poder P, Kivikko M (2007) Levosimendan vs dobutamine for patients with acute decompensated heart failure: the SURVIVE Randomized Trial. JAMA 297:1883-1891

51. Delaney A, Bradford C, McCaffrey J, Bagshaw SM, Lee R (2010) Levosimendan for the treatment of acute severe heart failure: A metaanalysis of randomised controlled trials. Int J Cardiol 138:281-289. doi: 10.1016/j.ijcard.2008.08.020

52. Jessup M, Abraham WT, Casey DE, Feldman AM, Francis GS, Ganiats TG, Konstam MA, Mancini DM, Rahko PS, Silver MA, Stevenson LW, Yancy CW (2009) 2009 focused update: ACCF/ AHA guidelines for the diagnosis and management of heart failure in adults: a report of the American College of Cardiology Foundation/American Heart Association Task Force on practice guidelines: developed in collaboration with the International Society for Heart and Lung Transplantation. Circulation 119:1977-2016. doi:10.1161/ CIRCULATIONAHA.109.192064 